\title{
Assurance ménage et responsabilité civile privée
}

\section{Maintenant réduisez vos frais}

\section{Conditions avantageuses pour les membres FMH}

Grâce à notre position sur le marché de plus grande organisation corporative de prestations de services nous pouvons négocier avec nos différents partenaires en assurances des conditions avantageuses pour nos membres. Nos conseillers professionnels sont présents dans toute la Suisse et vous offrent leurs compétences au lieu de votre activité.

\section{Notre offre dans le domaine de l'assurance ménage et responsabilité civile privée}

En collaboration avec l'assureur renommé Lloyd's, nous vous présentons en exclusivité un paquet de prestations d'assurances, spécialement préparé pour couvrir vos besoins personnels. Vous vous concentrez sur votre activité professionnelle, nous nous occupons de vos assurances - en toute sûreté.

\section{La comparaison ci-dessous vaut la peine d'être étudiée}

Somme d'assurance

Risques assurés
Fr. 100 000.- pour cet exemple Incendie, dégâts d'eau, vol avec effraction, détroussement, vol simple au domicile, vol simple hors du domicile (Fr. 2000.-)

(durée du contrat: 5 ans, timbre fédéral inclus)

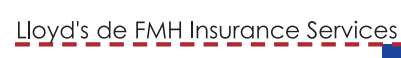

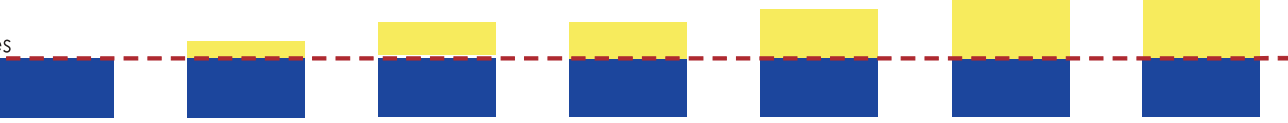

\begin{tabular}{|c|c|c|c|c|c|c|c|}
\hline Compagnie & Lloyd's & Züritel & Bâloise & Winterthur & $\begin{array}{c}\text { Coop } \\
\text { Assurances }\end{array}$ & Mobiliaire & Vaudoise \\
\hline Prime annuelle & 188.00 & 243.00 & 291.00 & 305.00 & 342.00 & 374.00 & 486.00 \\
\hline Différence en \% & & $+29 \%$ & $+55 \%$ & $+62 \%$ & $+82 \%$ & $+99 \%$ & $+159 \%$ \\
\hline
\end{tabular}

Source: www.comparis.ch

\section{Talon réponse}

Prénom / Nom

Adresse

NPA / Lieu

Date de naissance

Téléphone privé / cabinet

Atteignable le plus facilement (heure)

Je désire une offre personnelle. (Prière de joindre la copie de la police actuelle)

Somme d'assurance désirée

Je suis intéressé à:

Caisse de pension LPP C Caisse maladie

○ $3^{\text {ème }}$ pilier a

Planification financière

O
Protection juridique

Responsabilité civile profess.
Roth Gygax \& Partner SA $₫$ Service de coordination Moosstrasse 2 - 3073 Gümligen

Téléphone 0319595000 — Fax 0319595010 mail@fmhinsurance.ch $\square$ www.fmhinsurance.ch 